\title{
Con tierra de por medio: patrimonio, política y exilio de los Güell- Comillas en la España de entreguerras (1918-1945)*
}

\author{
Enrique Faes Díaz ${ }^{1}$ \\ Universidad Complutense de Madrid \\ efaes@ucm.es
}

\section{Sergio Riesco Roche ${ }^{2}$}

Universidad Carlos III de Madrid

sriesco@clio.uc3m.es

RESUMEN: El presente artículo tiene como objetivo analizar el periodo de entreguerras en España desde una óptica particular: la de cómo vivió esta procelosa época la casa Güell-Comillas, una de las grandes familias que construyó su patrimonio e influencia durante el siglo XIX. A partir de fuentes primarias diversas procedentes del Archivo Histórico Nacional, Arxiu Nacional de Catalunya, Centro Documental de la Memoria Histórica y Archivo del antiguo IRYDA, se estudia el papel desempeñado por Juan Antonio Güell López (tercer marqués de Comillas) y Juan Claudio Güell Churruca (conde de Ruiseñada) en la vida pública española durante el tracto cronológico de 1918 a 1945. Nos valemos de una combinación de prosopografia y acontecimiento histórico para aproximarnos al asunto tratando de observar la lógica interna del comportamiento de esta familia en una época que resultó especialmente conflictiva también para las élites. Las tensiones asociadas a la crisis de la Restauración, la Segunda República, la guerra civil y el primer franquismo no solo no alejaron a los Güell-Comilllas de su activismo económico y político, sino que los situaron

* Para la elaboración del presente artículo se han consultado documentos del Archivo Histórico Nacional, Madrid (AHN); Archivo del Instituto de Reforma y Desarrollo Agrario, Torrejón de Ardoz (AIRYDA); Archivo Militar de Segovia, Segovia (AMS); Arxiu Nacional de Catalunya, Sant Cugat del Vallès (ANC); y Centro Documental de la Memoria Histórica, Salamanca $(\mathrm{CDMH})$.

${ }^{1}$ ORCID iD: https://orcid.org/0000-0002-6310-8508.

2 ORCID iD: https://orcid.org/0000-0003-1429-8111.

Copyright: (C) 2018 CSIC. Este es un artículo de acceso abierto distribuido bajo los términos de una licencia de uso y distribución Creative Commons Reconocimiento 4.0 Internacional (CC-BY 4.0) 
en primer plano para participar, desde distintos lugares del arco conservador, de un tiempo tan complejo de forma muy activa y acomodaticia.

PALABRAS CLAVE: élites; influencia política; período de entreguerras; terratenientes; negocios; plutocracia.

With distance in between: the heritage, politics and exile of the Güell-Comillas in Spain in the interwar period (1918-1945)

ABSTRACT: The article aims to analyse the period between the two World Wars in Spain from a particular point of view, considering how this turbulent period was experienced by one of Spain's great families, the GüellComillas, who acquired their assets and influence during the nineteenth century. Using different primary sources from the Spanish National Historical Archive, the National Archive of Catalonia, the Documentary Centre for Historical Memory and the Archive of the former IRYDA, we study the roles played by Juan Antonio Güell López (Third Marquis of Comillas) and Juan Claudio Güell Churruca (Count of Ruiseñada) in Spanish public life between 1918 and 1945. We use a combination of prosopography and historical events to observe the internal rationale of this family's behaviour at a difficult time for everybody, even the elite. The conflicts arising from the crisis of the Restoration, the Second Republic, the Civil War and early Francoism, not only failed to remove the Comillas from their economic and political activism, but placed them centre stage giving them a particularly active and accommodative role, albeit from different positions on the conservative spectrum, at what was a highly complex time.

KEY WORDS: elites; political influence; interwar period; landlord; business; plutocracy.

CÓMO CITAR ESTE ARTÍCULO/CITATION: Faes Díaz, Enrique y Riesco Roche, Sergio, «Con tierra de por medio: patrimonio, política y exilio de los Güell-Comillas en la España de entreguerras (1918-1945)», Hispania, 78/260 (Madrid, 2018): 787-816. https://doi.org/10.3989/hispania.2018.019.

Este texto es fruto de una confluencia de objetos de estudio entre dos autores que intentábamos responder, por separado, a preguntas similares. Ambos veníamos calibrando la relevancia de la casa Güell-Comillas en la historia española contemporánea para explicar, con la ayuda de una bibliografía no muy profusa pero cada vez más sólida, cómo la fusión de dos grandes patrimonios familiares de origen indiano cuajó en una de las redes personales y empresariales más influyentes (y duraderas) en la España de entresiglos 3 . Pe-

3 Si bien existe bibliografía anterior que aborda de forma fragmentada alguna de las múltiples actividades de los Güell-Comillas, destacan en este punto los estudios de RODRIGO 
ro, ¿qué efectos tuvieron sobre esa capacidad de influencia la proclamación de la República, la guerra civil y la institucionalización del régimen franquista? ¿Qué actitud política adoptaron los nuevos depositarios de un vasto poder familiar acumulado durante medio siglo, y por qué motivo? ¿En qué medida se vio afectado su patrimonio? Conocemos con cierto detalle las trayectorias de los pioneros de esas dinastías que actuaron siempre enlazando intereses de élites asentadas en Barcelona y en Madrid. El relato se interrumpe, sin embargo, en plena crisis de la Restauración, cuando Juan Antonio Güell López (tercer marqués de Comillas) y su hijo Juan Claudio Güell Churruca (conde de Ruiseñada) tomaron el mando del ingente patrimonio familiar. El primero elaboró un personal discurso catalanista y partió al exilio. El segundo fue un entusiasta del régimen del que huía su padre. Nuestra propuesta consiste en trazar un recorrido paralelo por las vidas de ambos entre 1918 y 1945, es decir, en un momento de grandes cambios jalonado por los finales de las dos grandes guerras mundiales, para explorar cuáles fueron los mecanismos de adaptación de la casa Comillas a ese tiempo delicado. Hemos acudido a la mayor cantidad posible de fuentes primarias, varias de ellas inéditas, enfatizando las visiones que cada actor tuvo de su adversario, y nos hemos abierto a reformular el relato a partir de ellas y de otras aportaciones recientes.

\section{HACIA LA CRISIS DE LA RESTAURACIÓN: DÍAS DE VINO Y ROSAS}

Echemos, primero, la vista atrás. Entre 1874 y 1918, Juan Antonio Güell había vivido entre Comillas, Cambridge, Madrid y Barcelona, sin desdeñar la guerra de Marruecos, de donde se había traído dos heridas de bala. Un buen resumen del alcance de aquella trayectoria, y de cómo las herencias familiares habilitaron al joven López ${ }^{4}$ para ejercer el capitalismo a su antojo, lo firmó el periodista Adolfo Marsillach Costa en 1930:

Es un hombre afortunado el insigne prócer. Nació y todo lo encontró hecho. No ha tenido que luchar para nada. La fortuna familiar le ha puesto en las manos pala-

\footnotetext{
Y ALHARILLA, especialmente el publicado en 2001. En clave biográfica, y centrado en el segundo marqués de Comillas, está concebido también FAES, 2009. Del peso específico de la posesión de tierras en el patrimonio de la familia nos hemos ocupado en RIESCO, 2005. Son apreciables también las entradas elaboradas por Martín Rodrigo sobre Juan y Eusebio Güell para la compilación de CABANA, 2006. Y, aun considerándola una obra ciertamente mejorable en su profundidad y en su forma, debemos citar el reciente libro sobre los Güell de FARRÁS, 2016.

4 Para discriminar entre padre e hijo, en adelante nos valdremos del segundo apellido: nos referiremos a Juan Antonio Güell como López, y a su heredero Juan Claudio Güell como Churruca.
} 
cios, fincas urbanas, rústicas y de recreo; la dirección de fábricas y casas bancarias; la gerencia de la Trasatlántica; no sé qué explotaciones en Marruecos y otras muchas. Ha surcado todos los mares y conoce todos los países, viajando a lo gran señor 5 .

O lo que es lo mismo: López encajaba en el esquema propuesto por una novela que por esas mismas fechas transitaba con éxito por Europa. Al hablar sobre la imaginaria saga de los Buddenbrook, el premio Nobel Thomas Mann ofrecía a los historiadores un patrón según el cual el abuelo de una familia triunfante erige un imperio, el hijo lo dota de un sentido y el nieto propicia su decadencia. López podía encarnar este último papel por partida doble. El bebé nacido en Comillas casi con la Restauración se llamó Juan Antonio porque esa era la evocación conjunta de sus dos abuelos, los indianos Juan Güell Ferrer y Antonio López y López. En la segunda generación observó dos estilos paralelos, pero similares en el fondo, de orientar un gran patrimonio: su padre, Eusebio Güell, despuntó como gran mecenas barcelonés; su tío Claudio López volcó su actividad hacia el catolicismo social. Y mientras eso ocurría, y al calor de la pérdida de las colonias españolas de ultramar, emergió un catalanismo político conservador en el cual López recalaría pronto y en el que estaría llamado a desempeñar un papel importante. Así, el nieto de los GüellComillas pudo esmerarse como bachiller en Barcelona, relajarse a su paso por la Universidad (se licenció en Derecho con una media de aprobado, frente al sobresaliente del bachillerato) y trasladarse después a Madrid con el propósito, al alcance de una ínfima porción de los españoles del Novecientos, de obtener un doctorado ${ }^{6}$. La formación continuó en el extranjero. Hubo al menos una estancia de un par de años en Cambridge para perfeccionar el inglés y valorar sobre el terreno la cosmovisión conforme a la cual la Inglaterra victoriana se arrogaba un lugar importante en el mundo ${ }^{7}$. No es que aquel viaje cursado en los primeros años del nuevo siglo trasformara por completo al joven heredero, pero sí que debió influir en la construcción de su propio personaje público, si tomamos en cuenta que a su regreso a Barcelona llamaron la atención su porte de gentleman, su «feo vicio de fumar en pipa», los infaltables botines blancos con que caminaba, y la exasperación que provocaba en algunos de sus conciudadanos porque «hablando en castellano parece catalán, y hablando catalán parece inglés» ${ }^{8}$.

Más que su pretendida ecuanimidad (correlato, en realidad, de la exaltación del individualismo que cultivó durante toda su vida), la modernidad

5 ABC, 11/06/1930: 3-5.

6 Expediente personal de Juan Antonio Güell López, AHN, Universidades, 4216, exp. 4.

7 TARÍN, 84 (Barcelona, 1975): 90-103.

8 ABC, 11/06/1930: 4. 
cosmopolita con que decía afrontar el mundo, o la afirmación de que su educación lo había incapacitado para asumir soluciones políticas que no fueran estrictamente liberales, importa la sujeción de todo ello al retrato controlado que Güell quiso dejar de sí mismo recurriendo a casi todo lo incluido en el término life writing, es decir, elaborando diarios, memorias o autobiografías que distribuía con gusto entre sus amigos, amigas y semejantes de la alta sociedad europea $^{9}$. Así aseguró que en 1913 se había alistado como voluntario en Marruecos no por defender sobre el terreno los intereses económicos que su familia le había confiado en el norte de África, sino porque «es verdaderamente irritante que, cuando se trata de perder la vida, a la que tenemos derecho por igual los de arriba y los de abajo, no corran ese peligro más que los pobres $\rangle^{10}$. Si de ese modo López respondía al clamor contra el alistamiento forzoso que había desencadenado la Semana Trágica en los muelles de Barcelona («ique vaya Comillas, que vayan los hijos de Güell!»), se había demorado cuatro años en su respuesta ${ }^{11}$. Él mismo arguye que antes de enrolarse buscó durante un tiempo una solución parlamentaria a través de diputados afines, proponiendo la implantación del servicio militar obligatorio en tiempo de guerra para que los ricos no pudieran comprar su exención.

Pero la idea no prosperó y López se fue de voluntario al frente, muy probablemente para disgusto de Virginia Churruca y Dotres, con quien se había casado en 1904 y había tenido un hijo bautizado como Juan Claudio al año siguiente. Acudió al Regimiento de Cazadores de Vitoria (febrero de 1913), donde quedó registrado como un joven «propietario de edad 27 años. Su religión, C.A.R.; su estatura un metro y $700 \mathrm{~mm}$., pelo rubio, cejas al pelo, ojos azules, nariz regular, barba poblada, color sano, frente espaciosa, su aire marcial». En Tetuán hizo una carrera militar breve pero fulgurante. En abril ya era cabo de caballería, y el Alto Comisario de España en Marruecos propuso su ascenso a sargento en agosto como reconocimiento de «su serenidad y acierto» en las operaciones. López había destacado «hostilizando a grupos de moros», había garantizado retiradas con éxito y había escoltado convoyes de municiones y heridos. Había descollado también en acciones «para arrasar varios poblados», y sin embargo (o tal vez por ello) escribía que «ha de tener muy pobre juicio del perfeccionamiento humano quien no crea que en fecha no lejana se llegará al desarme universal». Dos grandes lecciones decía haberse traído de África, en vísperas de que los avances militares permitieran al fin la normal actividad de empresas como la Compañía Española de Minas del Rif, de la que era accionista destacado: un profundo desprecio por la gue-

9 Una reflexión sobre la utilidad del término, traducible como escrituras del yo, en BURDIEL, 2014: 56-57.

10 GÜELL, 1926-1929, vol. I: 153-154.

11 ROMERO MAURA, 1989: 501-502. 
rra y la comprobación de que la «Raza» española, que legítimamente podía y debía ocupar su territorio marroquí asignado en el reparto con Francia, era todo «virtudes y temple». En septiembre del mismo 1913 pidió una licencia y alcanzó el grado de alférez en la reserva ${ }^{12}$.

Lo siguiente fue el ingreso en la nobleza. Pasados los 40 años de edad sin título nobiliario propio, López logró que Alfonso XIII rehabilitara para él en 1916 el condado de San Pedro de Ruiseñada, una pedanía próxima a Comillas ligada a la forja de la leyenda familiar. Pero apenas tuvo tiempo de ostentar esa distinción. Dos años después, en 1918, falleció en su residencia barcelonesa su padre Eusebio Güell, gran mecenas de Gaudí, y López heredó de él el título de conde de Güell. Automáticamente, el joven Juan Claudio (Güell y Churruca) se convirtió entonces en conde de Ruiseñada. La fecha en que se produjo este trasvase de títulos - y que hemos tomado como punto de partida de nuestro relato-, fue específicamente importante en Barcelona, ya que la historiografía no duda en señalar el tracto cronológico entre 1918 y 1923 como el más complejo de la conflictividad social en la ciudad, con más de 350 víctimas de la violencia política de variado signo ${ }^{13}$. La patronal, agrupada en el Fomento del Trabajo Nacional (organismo cuyo germen había fundado en 1869 el patriarca de la familia, Juan Güell), se refería con espanto al «pánico de 1919» y buscaba por esas fechas conciliar los intereses políticos y económicos en un frente capaz de contener al pistolerismo anarquista.

En ese contexto nació, en enero de 1919, el somatén de Barcelona. Un joven Marcelino Domingo indicaría entonces que aquella institución era «la fusión en clase social de la Unión Monárquica y la Lliga Regionalista» ${ }^{14}$, en una organización cuyos resortes monopolizaban «terratenientes, nobles, grandes industriales y financieros». Allí confluirían «regionalistas catalanes de la Lliga, nacionalistas españoles de la Unión Monárquica Nacional y carlistas» ${ }^{15}$. Toda una «fuerza armada financiada por industriales y organizada por el ejército» que, a los efectos de este trabajo, bien puede considerarse una plataforma de encuentro entre el catalanismo moderado que formuló López y la sensibilidad monárquico-carlista hacia la que enseguida se decantó su hijo Churruca, implicados ambos sin duda en la forja de aquella entidad ${ }^{16}$. En todo caso, debemos subrayar que si hay algo en lo que padre e hijo coinciden en-

12 Expediente de Juan Antonio Güell López, AMS, exp. G-4082. GÜELL, 1926-1929, vol. I: 228-232. Para los intereses de los Güell-Comillas en el norte de África, véase RODRIGO, 2001: 312-315.

13 PRADAS BAENA, 2003: 319.

14 DEL REY y GONZÁLEZ CALLEJA, 1995: 95.

15 QUIROGA, 2014: 216.

16 Conviene no perder de vista la actitud del segundo marqués de Comillas a este respecto. Véase FAES, 2009: 288 y ss. 
tonces, es desde luego en la incondicionalidad respecto a la monarquía de Alfonso XIII, ejemplificada en el hecho de que en aquellos años convulsos López pusiera todo de su parte - su tiempo, sus fincas, sus medios financieros-, para dotar a Barcelona de una sede monárquica de primera magnitud: el Palau Reial de Pedralbes.

Mientras las obras avanzaban, Churruca partió a estudiar Derecho en Inglaterra. Allí conocería (1925) el fallecimiento de su tío abuelo Claudio López Bru, segundo marqués de Comillas. Habían transcurrido apenas siete años después de la desaparición de Eusebio Güell, y aquella nueva muerte terminó de mover los resortes de una herencia ingente y convirtió a López en depositario de un gran legado que incluía propiedades repartidas por Cataluña, Extremadura y Comillas, pero sobre todo una importante cartera de valores con participaciones en todos los sectores estratégicos de la economía española (véase la tabla número 1).

\section{CONSOLIDACIÓN SOCIAL EN UNA DÉCADA MEMORABLE (1918-1928)}

Claudio López Bru, ya anciano, no había tenido tiempo de participar en primer plano en la dictadura de Miguel Primo de Rivera. Ese papel lo asumió su heredero. Si a los contactos trabados en, o a propósito de Marruecos por Juan Antonio Güell (allí se puso a las órdenes de Dámaso Berenguer y se hizo amigo del general José Marina, enviado a Barcelona en el crítico 1917) sumamos la percepción de desorden social desde posiciones conservadoras y, desde luego, la larga tradición de complicidad entre los capitanes generales de Cataluña y los grandes propietarios del Principado, poco extraña que López defendiera hasta el final el golpe de Estado que Primo, otro de sus señalados amigos militares, había liderado precisamente desde la capital catalana en 1923. Aún en vísperas de su caída lo exaltaría como «el ilustre caudillo que en el momento de mayor peligro levantó su espada para defender la causa del orden, imponiéndolo y dando así a España la era de prosperidad que disfrutamos» ${ }^{17}$. Y avanzados ya los años cuarenta resumiría con menos entusiasmo, pero con tono indulgente, hasta qué punto Primo había traído al país una etapa de calma, modernización y prestigio exterior inédito $-\mathrm{y}$ aquí exageraba un poco-, en el último siglo. Su gobierno, decía López, había sido honesto e inteligente, pero se habría estrellado contra «el egoísmo en el problema social» y el «ideal personal» de catalanes y vascos ${ }^{18}$.

No pareció importante el alejamiento que el propio Juan Antonio Güell sugirió entre ambos en cuanto el general liquidó la autonomía catalana. Si

17 La Época, 04/11/1929: 1.

18 GÜELL, 1946: 15-19. 
existió esa brecha, nunca fue insalvable. Después de jalearle en las horas previas al golpe, de saldar incluso de su bolsillo unas deudas de juego que atormentaban al general porque si algo necesitaba antes de desmarcarse era decía-, exhibir su honra intacta, López se incorporó de lleno a la administración primorriverista como presidente del Patronato Nacional del Turismo, creado en abril de 1928. Ya había puesto su mirada en el nuevo negocio turístico, dos años antes, como un medio idóneo para equilibrar la balanza comercial de España. Y había enviado a su hijo a analizar una empresa londinense pionera en la venta de viajes a la Península. La fagocitación del organismo por los Güell-Comillas y su Compañía Trasatlántica (una decena de parientes y hombres de confianza de la familia entraron en el organigrama del Patronato, y los intereses de la naviera estuvieron siempre en el foco de sus administradores) no debe anular el efectivo ensayo de modernización turística del país que el tercer marqués de Comillas lideró, antes de que el fin de la dictadura y una nueva crisis económica abortaran el intento. Se multiplicó la red de oficinas de información al viajero, se actualizó de forma notable la propaganda y se construyeron complejos como el Hotel Atlántico de Cádiz, inaugurado por López en 1929, que si bien resultaron demasiado colosales sí que señalaron el camino del vuelco estatal hacia un sector económico que habría de tener largo recorrido ${ }^{19}$. "Realmente se ve que los del Turismo lo estáis haciendo admirablemente. Las carreteras, hoteles, etc. están a la altura de los países más civilizados», escribía una de sus corresponsales a Güell López, deslumbrada tras veranear en Comillas ${ }^{20}$.

Otras damas de la alta sociedad reconocían implícitamente la identificación del marqués con el Patronato, rogándole la colocación de algún favorecido como inspector de Paradores o sugiriéndole incluso que el suministro de ropas a aquella entidad gigante se le asignara en exclusiva a la Acción Católica femenina. Cuando Amalita Buenavista solicitaba ambas cosas, revelaba por cierto que había estado leyendo unas memorias que el propio López le había facilitado, «que encuentro interesantísimas», y con su carta engordaba una carpeta donde el marqués de Comillas iba acumulando otras misivas semejantes. Por ellas sabemos que López adoraba viajar «a lo gran señor» tal como consignó Marsillach, que se esforzaba en agradar a sus pares y que se prodigaba en una amplia vida social con una ostentación propia de su clase. Tan pronto enviaba una colección de discos al domicilio de una de sus amigas en Turín, a lo que ésta respondía "ime encantan, pues son verdaderamente españoles y son preciosos!», como recibía de otra de ellas las «gracias por todas y cada una de tus bondades, que casi me tienen avergonzada», o man-

19 MORENO, 2010.

20 Carta de Cristina Camarasa a Juan Antonio Güell, 11/09/1929, ANC, fondo GüellComillas, 04.02.01.

Hispania, 2018, vol. LXXVIII, $\mathrm{n}^{\circ}$. 260, septiembre-diciembre, págs. 787-816, ISSN: 0018-2141, e-ISSN: 1988-8368 https://doi.org/10.3989/hispania.2018.019 
daba regalar un soberbio ejemplar de mastín a los marqueses de Torralba de Calatrava en el transcurso de una visita de recreo a la finca de El Alamín. De su entrega como anfitrión da buena fe la gratitud de la princesa sin trono María Antonia de Braganza, quien poco después de compartir mesa presidencial con López en la inauguración de aquel gran hotel gaditano partió hacia Barcelona en un automóvil guiado por el chófer del marqués y anotó a su llegada: «Me has enseñado a amar los viajes, ya sabes. Gracias de nuevo por todo» ${ }^{21}$.

Con el padre entregado, pues, a la promoción del turismo, 1928 significó también la puesta de largo de Juan Claudio Güell Churruca. El año comenzó con un gran regalo: la transmisión de padre a hijo del título de conde de Ruiseñada, cuyo nombre apocopado - Ruiseñada-, lo identificaría desde entonces en la vida pública ${ }^{22}$. Luego de terminar sus estudios de Derecho y perfeccionar su inglés en el condado de Kent, Churruca había realizado su servicio militar, primero en la caja de reclutas de Barcelona y más tarde en el Regimiento de Dragones de Santiago, licenciándose como sargento de complemento en abril de $1927^{23}$. Todo parece indicar que aquel título nobiliario fue el principal regalo de boda de López a su primogénito, ya que éste contrajo matrimonio en septiembre de 1928 con María Angustias Martos y Zabalburu, una hija del marqués de Iturbieta, persona muy próxima a la monarquía y distinguida con la Grandeza de España ${ }^{24}$. Aunque el enlace se celebró en Bilbao, la familia pasó largas temporadas en su casona donostiarra Villa Oroimena (memoria, en euskera), ubicada en las inmediaciones del palacio de Miramar. Se entrelazaba así lo comercial y lo social: al tiempo que aquella localización permitía ampliar las actividades de la Compañía Trasatlántica en el cercano puerto de Bilbao, ofrecía un lugar privilegiado para acompañar a la familia real en sus vacaciones de verano junto al Cantábrico. Y si no era allí, sería en Extremadura. En ese mismo año 1928, significativo para los Güell-Comillas por cuanto cerraba para ellos toda una década dulce (a la doble herencia del condado de Güell y del marquesado de Comillas la culminaban ahora el reconocimiento social de la monarquía y la integración política en la dictadura), el joven Churruca y su esposa alojaron a Alfonso XIII y a Primo de Rivera en el palacete familiar de Las Cabezas aprovechando un viaje regio para la coronación canónica de la Virgen de Guadalupe. De ahí nacería una vinculación

21 Cartas de Amalita Buenavista, Cristina Pignatelli, marqueses de Torralba de Calatrava y María Antonia de Braganza a Juan Antonio Güell, 10 y 11/1929, ANC, fondo Güell-Comillas, 04.02.01. Agasajos como esos a la alta sociedad fueron comunes en las propiedades que los Güell-Comillas regentaron en Comillas, Toledo y Extremadura.

22 Real orden disponiendo se expida Real carta de sucesión en el título de Conde de San Pedro de Ruiseñada, a favor de don Juan Claudio de Güell y de Churruca, Boletín Oficial del Estado, 20/07/1928, nº 202.

23 Hoja Matriz de Servicios de D. Juan Claudio Güell Churruca, AMS.

$24 A B C, 07 / 10 / 1928$. 
permanente con la reina Victoria Eugenia, pues los condes de Ruiseñada pasaron a tomar un inusitado protagonismo como miembros (gentilhombre y dama) de la Casa de S.M.la Reina.

Fue precisamente el rey quien autorizó, en última instancia, el nombramiento de Juan Antonio Güell López como alcalde de Barcelona en 1930 tras la caída de Primo. Defender la legitimidad del golpe del general no estaba reñido para López con admitir que aquella solución autoritaria había sido anómala por lo menos en la forma, sobre todo si pretendía autorretratarse como un moderno liberal de convicciones democráticas. Su primer viaje a Madrid como alcalde tuvo de hecho por objeto comunicarle al gobierno central que la vida catalana volvía «a la normalidad», sin estridencias, en el tránsito de algo que ya se reconocía como una dictadura a otra de perfil más bajo que aún no se designaba como tal25. Aquel elocuente relato ya citado de Adolfo Marsillach, abuelo del dramaturgo homónimo, sirve también para explicar cómo habría accedido Güell López al Ayuntamiento barcelonés:

La Alcaldía la obtuvo de momio (...). Indicóle el Sr. Cambó para este cargo, y el Gobierno del general Berenguer extendió el nombramiento, siendo bien acogido por la ciudad. No entró (...) como un caballo loco, soliviantando el sector separatista con actitudes de alcalde de Cork (...). Tampoco el actual conde de Güell ha hecho del separatismo un chantaje. Para la buena marcha de sus negocios no ha enconado, utilitaria y criminalmente, el problema catalán. Su regionalismo, más sentimental que político, es compatible con la unidad nacional. El conde de Güell es muy catalán, pero muy español también ${ }^{26}$.

Más adelante ahondaremos en esa aparente dualidad. Frente a la imagen proyectada en su entorno que le atribuía una vida política casi nula hasta la fecha, López se encargó de recordar que si en los albores del régimen de Primo había participado en el entierro de Ángel Guimerà, muy vigilado por la policía Rambla abajo por cuanto aquella concentración pudiera tener de vindicación catalanista, gestos como aquel formaban parte de toda una actuación personal desplegada «entre bastidores» durante los años veinte a propósito del «llamado problema catalán». Su actitud al respecto, escribió el aristócrata, siempre fue de mediación o «pasteleo: consecuencia de intervenir entre dos que se pelean y de creer que ninguno de los dos tiene toda la razón» ${ }^{27}$. Pero en todo caso, fue una figura próxima a Cambó en todo el período, lo que debió ser decisivo para tomar posiciones en aquel tiempo de dudas sobre el futuro de la monarquía. Asumió la alcaldía en febrero de 1930, en una sesión tumultuosa preanunciada ya por la aparente fragmentación ideológica de

\footnotetext{
25 La Veu de Catalunya, 23/03/1930: 11.

26 ABC, 11/06/1930: 3-5.

27 GÜELL, 1926-1929, vol. I: 85-97 y vol. IV: 10-11.
} 
quienes integraban la comisión permanente: tres regionalistas, dos representantes de Acció Catalana, dos radicales y los tres mayores contribuyentes locales. Su discurso inicial fue toda una expresión de doble pertenencia, con un tema infalible: el canto nostálgico a la Barcelona medieval. Dijo aceptar el cargo «por orgullo de España y de su monarca», aludiendo así al último responsable de su designación (Alfonso XIII), y al mismo tiempo anunció que hablaría en catalán, lo que provocó «una ovació formidable i seguidament alguna confusió» ${ }^{28}$.

No debe sorprender que en los doce meses que López fue alcalde de Barcelona la ciudad no registrara transformaciones extraordinarias. Por la brevedad y la transitoriedad del periodo, pero también porque el alcalde concebía el Ayuntamiento como una entidad que debía ser eminentemente administrativa, lejos de la acción política. Como mucho, podía ser un instrumento para esa conciliación entre España y Cataluña que López entendía tan conveniente seguramente porque unas cuantas familias como la suya la venían encarnando con provecho, y enfocada ésta en todo caso en una confluencia cultural. Dedicó su primer acto público a homenajear al periodista Joaquim Rubió i Ors, adhiriéndose en su alocución a la «glorificació del gran campió de la renaixença de la parla catalana». Y a renglón seguido hizo lo propio con los intelectuales castellanos. Ante figuras de la talla de Manuel Azaña, Gregorio Marañón o José Ortega y Gasset, el alcalde López reivindicó una herencia compartida en la que igual cabía Manuel Milà i Fontanals que Marcelino Menéndez y Pelayo; precisó que Cataluña, indómita por naturaleza, se había unido «libremente a Castilla por pactos forales de respeto a mutuas libertades»; y advirtió a los catalanes contra la tentación de «la intransigencia, las imposiciones y el imperialismo miniaturizado» ${ }^{29}$. No hubo demasiado tiempo para más. López se retiró a Francia en abril de 1931, a la espera de conocer si las urnas validaban su candidatura - ahora sí-, como alcalde democrático, y desde allí asistió al derrumbe de la monarquía.

\section{«SIN QUE SE SEPA CÓMO NI POR QUÉ»: LOS GÜELL DURANTE LA REPÚBLICA}

Lo siguiente que sabemos de él es que en julio de 1931 preparó un viaje a los montes Cárpatos como padrino de bodas del príncipe Antonio de Habsburgo, que se disponía a casarse con la princesa Ileana de Rumanía. Allí, en la pequeña localidad de Sinaia, en tiempos críticos para las monarquías europeas de los que mucho podían decir los infantes españoles o los depuestos reyes de Grecia (todos presentes en el evento), se concentró - y es presumible que

28 La Veu de Catalunya, 27/02/1930: 1.

29 La Veu de Catalunya, diversos números entre 05/03/1930-23/03/1930. 
reforzara su sentimiento de legitimidad para vindicar cuanto le pertenecía o acababa de perder-, la realeza del continente ${ }^{30}$. Seguramente se refería López a personajes como aquellos cuando, en una de sus piruetas retóricas, censuraba la actitud con que sus colegas de las clases altas catalanas recibieron la proclamación de la II República. Anclados en viejos privilegios y desde luego temerosos de perderlos, decía el ya ex alcalde de Barcelona, no es que su posición fuera ultramontana: es que carecían, en su conjunto, de tradición política alguna. Representaban la frivolidad, el pasado. Por eso López decía distanciarse de ellos y habilitaba un discurso para hermanarse, él mismo, con una clase media que caracterizaba como «la más poderosa, motor social y político del país [catalán]», abierta a las proclamas democráticas y autonomistas de Manuel Azaña y capaz de guiar muy prudentemente a un pueblo al que, más que la forma que pudiera adoptar el Estado, le preocupaba mejorar sus condiciones de vida ${ }^{31}$.

Si en lo político su actitud resultaba acomodaticia, menos negociable era la estética. No le gustó a López el cambio de una bandera «prestigiosa» en el mundo por otra que a su juicio no significaba nada, y mucho menos aún el himno de Riego, «de inspiración musical deplorable, donde la vulgaridad alcanza el límite de lo grotesco». Había que evitar la irrupción de lo vulgar. Si Cataluña había decidido romper con el sentimiento monárquico, una de las dos «únicas raíces populares de nuestro organismo social» (la otra era la religiosidad católica), al menos debía proceder con elegancia, y en ese sentido moduló Juan Antonio Güell López su discurso. Cataluña sí que podía esgrimir, y hasta glorificar, una bandera que simbolizaba «viejas victorias». Y allá estaba, en palabras del conde, la figura venerable de Francesc Macià, cuyo prestigio acrecentaba en las ceremonias oficiales «el ritmo solemne de Els Segadors $»^{32}$. Muchos años más tarde, López cerraría su explicación asegurando que, si bien había determinado su «incompatibilidad» con la República como gran monárquico que siempre fue, «debía acoger con agrado las conquistas del catalanismo». Afirmaba algo más: mucho había sufrido por la persecución que las autoridades republicanas desencadenaron enseguida contra la más emblemática de las empresas familiares, la Compañía Trasatlántica, intervenida en su día por Primo de Rivera para mejorar su solidez pero pronto desechada en su relación con el Estado por la antigüedad de su flota y una contabilidad tramposa ${ }^{33}$. Todavía en 1933 eran habituales los viajes de López a Madrid para resolver asuntos relacionados con la empresa que presidía. Se alojaba en los hoteles Ritz o Savoy, se desplazaba siempre en taxi y no des-

30 L'Homme Libre, 09/07/1931: 3.

31 GÜELL, 1946: 18-19.

32 GÜELL, 1946: 19 y ss.

33 TARÍN, 84 (Barcelona, 1975): 101. 
deñaba la ocasión de adquirir en la capital un par de buenas corbatas o de almorzar en la recién abierta cervecería Baviera, un refinado local de la calle de Alcalá donde a diario se recibía caviar llegado en avión de Rusia ${ }^{34}$. Estar al frente de la Trasatlántica aún le reportaba en vísperas de la guerra civil unos ingresos personales de 33.559 pesetas al año, una suma algo inferior a su asignación como presidente de Tabacos de Filipinas, pero por delante de las obvenciones que le correspondían en otras sociedades como la Ford, Carburos Metálicos o la heredada Colonia Güell. Solo por el rendimiento del capital invertido en esta última firma, López ingresó en 1935 un total de 31.566 pesetas. Pero la clave de su holgada posición económica residía en lo que estaba fijado al suelo. Casi dos tercios del capital que Juan Antonio Güell López declaró haberse embolsado a lo largo de ese año previo al golpe de Franco procedía de la explotación de fincas e inmuebles familiares en Barcelona, Cantabria, Toledo y Extremadura. Fueron algo más de 360.000 pesetas, frente a las casi 134.000 obtenidas como presidente o consejero de distintas empresas y a las 66.713 que le reportaron los cuantiosos capitales invertidos en sociedades bancarias, aseguradoras e industriales. Más de medio millón de pesetas al año, en suma ${ }^{35}$.

Tal balance de ingresos denota que los rendimientos de las explotaciones agropecuarias eran más importantes que sus haberes como empresario manufacturero o del transporte. Casi medio siglo después de la muerte del fundador de la saga, Antonio López, seguía en perfecto estado de salud su voluntad de que «los bienes inmuebles deben representar un valor igual de la tercera parte de mi herencia» ${ }^{36}$. Así, a los viejos viñedos de Santa Perpetua de Moguda y El Garraf se unían la finca El Alamín (Toledo), en cuyas más de 1.600 hectáreas tuvieron lugar célebres cacerías durante el franquismo, y sobre todo las posesiones de Extremadura: un «coto redondo» superior a las 20.000 hectáreas de extensión, con linderos en una decena de pueblos de la comarca cacereña del Campo Arañuelo.

La política de compras de la familia, planificada, se había mantenido activa al menos hasta los años veinte. Se puede hablar de cierta actitud predadora por parte de los Comillas y sus testaferros en la zona: preguntado en plena República por el origen de ciertos predios, el alcalde de Almaraz (Cáceres) relataba cómo varias dehesas habían ido a parar al Marquesado de Comillas «sin que se sepa cómo ni por qué» ${ }^{37}$, y había quien recordaba que el vuelo de

34 ANC, fondo Güell-Comillas, 02.02.22.

35 Contribución de Juan Antonio Güell, AHN, FC, Hacienda, 7098, exp. 171.

36 RODRIGO, 2001: 145.

37 Respuesta del Secretario de la Subcomisión de Bienes Comunales de la Comisión Técnica Agraria del Ministerio de Trabajo, 25/09/1931, AIRYDA, Fondo Señoríos y Comunales. 
la dehesa boyal de Navalmoral había pasado a su propiedad a pesar de existir sentencias judiciales en sentido contrario ${ }^{38}$. Así las cosas, y ante la dificultad extrema de una eventual gestión directa, fue la familia Del Mazo Satrústegui - viejos amigos de los Comillas en los primeros tiempos de la Trasatlántica-, la que administró por delegación todas las fincas del Campo Arañuelo con una estructura cuyo manejo no debió ser sencillo, pero que sí fue un escenario propicio donde obtener pingües beneficios ${ }^{39}$.

La reforma agraria republicana afectó de lleno a las propiedades de los Güell-Comillas, que figuraban en sexto lugar entre los Grandes de España según número de hectáreas declaradas. De las más de 23.000 que declararon poseer, les fue expropiado un 58 por ciento, lo que les convirtió en la familia de la Grandeza más afectada ${ }^{40}$. Así interpretaron esa enajenación:

A estos labradores se les hizo objeto predilecto de todas las ideas subversivas (...), se distribuyeron en la zona toda clase de libros y folletos y vinieron a vivir gentes extrañas que se erigieron en dirigentes de las sociedades que se crearon (...). Los mayores enemigos del marxismo son todos los que con sus buenas obras ponen de relieve el horror y la utopía de tan disolventes doctrinas. Por esta causa, el odio de los dirigentes revolucionarios, desde Azaña y Giral hasta la Pasionaria y células repartidas por esta comarca de Extremadura, se dirigió contra el Marqués de Comillas y sus fincas fueron las primeras de las que se incautó el Instituto de Reforma Agraria ${ }^{41}$.

Ante la expropiación, hubo dos vías de resistencia directa o indirecta por parte de Churruca, quien se encargaba entonces de las fincas familiares: la obstrucción física y la vía judicial. Fue constante la resistencia de las tres grandes familias de ganaderos beneficiadas por el arrendamiento de los pastos - Camacho, Madrigal, Carreño-, que defendían su antiguo derecho inmovilizando a su ganado cada vez que las nuevas comunidades de campesinos pretendían ponerse a trabajar ciertas parcelas. La Guardia Civil actuó para desalojarlos, pero nunca fue fácil. Su estrategia diletante les resultó producti$\mathrm{va}^{42}$. En cuanto a la obstrucción judicial, la Casa Comillas no recurrió por criterios técnicos a la expropiación, tal y como hicieron otras familias, sino que rastreó algún defecto de forma para frenar el proceso. Como la República había inventariado las fincas enajenables a nombre de Juan Antonio Güell

38 Informe del ayuntamiento de Navalmoral de la Mata a la Comisión Técnica del ministerio de Trabajo, 27/06/1931, AIRYDA, Fondo Comunales, legajo 45.

39 ALVARADO y PAREJO, 2016. RIESCO, 2005: 236 y ss.

40 ROBLEDO, 2014: 382.

41 ANC, fondo Güell-Comillas, legajo 24, s.f. y sin autor. Sabemos, por la correspondencia de Juan Claudio, que se trata de un encargo a un miembro de la familia Madrigal, gestora de la Casa Comillas en Navalmoral.

42 AIRYDA, Fondo Reforma Agraria, Cáceres, legajo 36. 
López, pero en realidad estaban ligadas al fideicomiso instituido por Claudio López Bru en su testamento (y su esposa seguía viva), los abogados de la casa argumentaron que la expropiación no procedía. No tuvieron éxito. El Instituto de Reforma Agraria determinó en su inventario que los derechos que sobre las tierras «puedan ejercitar el posterior o posteriores fiduciarios» quedarían a salvo, pero que eso no impedía su inclusión en la lista de fincas expropiables ${ }^{43}$.

Güell Churruca, conde de Ruiseñada, pasó a la política activa durante los años 30 y financió tanto la revista Acción Española como la asociación Renovación Española, ambas lideradas por Eugenio Vegas Latapié ${ }^{44}$. Toledo pudo ser la ciudad donde esta confluencia hacia una solución monárquica y de derechas sentó las bases del futuro Bloque Nacional, ya que en la directiva local de Renovación Española coincidieron, en torno al ex ministro José Calvo Sotelo, el propio Ruiseñada, José Félix de Lequerica — próximo a la Trasatlántica-, y Alfredo Van der Brule, próximo al conde por su conexión con el País Vasco ${ }^{45}$. No faltó Churruca a la ocasión de aportar algo a la represión de la revolución de 1934:

Se presentó como voluntario en la Comandancia Militar de San Sebastián con ocasión del movimiento revolucionario de octubre de aquel año el día 8 de dicho mes prestando servicios hasta el día 19 de noviembre, siendo felicitado por sus servicios y propuesto para una recompensa militar por dicho Comandante Militar ${ }^{46}$.

Poco más sabemos de su actividad antirrepublicana. Las escasas referencias a este periodo nos lo presentan siempre en el entorno de Calvo Sotelo, animado por Victoria Eugenia a que Alfonso XIII abdicara en su hijo Don Juan y, por tanto, cercano a Vegas Latapié y a Pedro Sáinz Rodríguez. Teniendo en cuenta su peso social en San Sebastián y su proclividad al intervencionismo militar, es factible que favoreciera la implantación de la Unión Militar Española, tan decisiva en el golpe de Estado del 18 de julio de 1936. «Su reconocido patriotismo le llevó a colaborar en la preparación del Movimiento Nacional», aseguró $A B C$ en su obituario sin mayor precisión ${ }^{47}$. Lo que sí se conoce es que Churruca había sido uno de los habituales de la OLSA, la oficina que en 1933 habían creado Sáinz Rodríguez y Sangróniz para centralizar los recursos contra las expropiaciones de tierras planteadas por la República y que, además de cumplir esa función ${ }^{48}$, conectó a los civiles de Renovación

43 Actas del Consejo Ejecutivo del Instituto de Reforma Agraria, 27/09/1933.

44 GONZÁLEZ CUEVAS, 1998: 127. DÍAZ HERNÁNDEZ, 2008: 293.

45 RUIZ ALONSO, 2011: 51.

46 Hoja de servicios de Juan Claudio Güell Churruca, AMS, página 5.

47 ABC, 25/04/1958: 28.

48 Un primo hermano de Churruca refiere también la existencia de la oficina. Véase BERTRÁN, 1939: 101. 
Española con los militares de la Unión Militar. Allí coincidieron apellidos tan relevantes para el futuro golpe de Estado como Galarza, Kindelán, Serrano Súñer o Muñoz Grandes ${ }^{49}$. En esa conjunción de monárquicos alfonsinos, carlistas y algunos falangistas encontramos a Juan Claudio Güell Churruca, cuando la conspiración comienza a tomar ritmo a partir de marzo de $1936^{50}$. En aquel ambiente se encontraría también Ignasi Ventosa, el hijo de Joan Ventosa, muestra de los estrechos lazos que unían a un sector del catalanismo político con los golpistas. Sería precisamente uno de estos falangistas omnipresentes en la OLSA, Francisco Moreno y Herrera, quien lo acompañaría a Cannes en los primeros compases del golpe: querían obtener el beneplácito de la reina Victoria Eugenia para que Don Juan se incorporara al bando sublevado ${ }^{51}$.

\section{DISTINTOS CAMINOS EN 1936: UN HIJO ENTUSIASTA DEL FRANQUISMO...}

Ajeno a los movimientos políticos in crescendo de su hijo, el 18 de julio de 1936 Juan Antonio Güell López se encontraba en Ibiza. Había viajado allá, a sabiendas ya del asesinato de Calvo Sotelo (que precipitaría el golpe), para redactar un discurso que habría de pronunciar ante la Real Academia Catalana de Bellas Artes de Sant Jordi, de la que era presidente desde 1928. Se había replegado hacia la cultura, casi puede decirse que hacia posiciones sobre todo estéticas, especialmente tras la llegada de la República, y eso le ha valido la reciente vindicación desde cierto catalanismo cultural que de algún modo secunda y celebra su discurso: lejos de haber sido un personaje «convencional» cuyos méritos se basan únicamente en su alta extracción social, López habría engrosado esa moderna vanguardia catalana a caballo entre una impetuosa clase media y una nueva nobleza que ya no asienta su liderazgo sobre hechos de armas, sino a partir de «aportaciones importantes a la salud económica del país». Celebridades como él — hoy minusvaloradas-, encajarían en el arquetipo del self made man que se llena de legitimidad para guiar a sus semejantes hacia un futuro ordenado, pleno de autoestima, y vendrían a probar que el reconocimiento de la «personalidad catalana» conoció grandes avances en el siglo pasado gracias a posiciones como la de López, «contemporizador y posibilista» ${ }^{52}$. Una versión del seny como virtud distintiva.

49 CALLEJA Y LÓPEZ, 1963: 77-78.

50 GONZÁLEZ CALLEJA, 2011: 353. GIL ROBLES, 1968: 694.

51 PEÑA GONZÁLEZ, 2003: 129-130.

52 FONTBONA, XXII (Barcelona, 2008). Además de elaborar desde los años veinte las obras de tono autobiográfico que venimos citando, Juan Antonio Güell López reunió una importante colección personal de escultura religiosa que él mismo presentó, catalogada, en 1925, y publicó en 1935 tres ensayos o discursos con la cultura catalana como eje narrativo: 
A partir de aquí, los caminos se bifurcaron sin remedio. Retenido el padre en Baleares con sus apuntes bajo el brazo y sus reflexiones catalanistas en mente, Churruca se presentó el 21 de julio «como voluntario al Glorioso Movimiento Nacional, pasando a prestar sus servicios por orden de la Junta de Defensa Nacional en la organización de todos los trenes militares de municiones y militarización del personal de la Compañía de Ferrocarriles $\rangle^{53}$. Se entregó después con fervor a la causa golpista. Su hoja de servicios relata su ingreso en la Escala de Complemento Honorario de Ferrocarriles como capitán, actividad que simultaneó con un cargo en la Junta Técnica del Estado como vocal en su Comisión de Obras Públicas y Transportes debido probablemente a que en ella se integraban intereses tan sensibles para él como la navegación y los ferrocarriles. Es posible que llegara hasta Burgos a través de Joaquín Bau, presidente de otra de las comisiones, un destacado tradicionalista catalán que se convertiría en ministro de Industria en otra muestra de la compleja trama de intereses ideológicos y económicos presentes en la Cataluña de los años treinta ${ }^{54}$.

Entre marzo y septiembre de 1937 Juan Claudio Güell Churruca participó en los combates del frente de Vizcaya, permaneciendo a continuación en Burgos hasta abril de 1938 con un doble perfil: miembro destacado de la Jun-

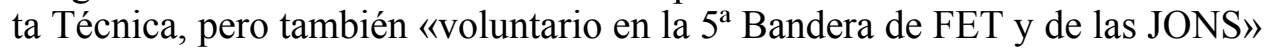
de la localidad 55 . Inició luego el camino hacia el grado de teniente de complemento al incorporarse, en Zaragoza, al Regimiento de Cazadores de los Castillejos en su división de caballería, y desde ahí se sumó a la Batalla del Ebro (frente del Segre), donde resultó herido y tuvo que ser evacuado. Sin duda Churruca estuvo en primera línea ${ }^{56}$. Defendía las centrales hidroeléctricas cuyo control debería impulsar el asalto final de los golpistas a Cataluña, el feudo industrial e institucional de los Güell-Comillas, pero se perdió ese mo-

La Musa Catalana: Geographos, Tres imatges (tres evocacions) y Elogi de la cultura catalana.

53 Hoja de servicios de Juan Claudio Güell Churruca, AMS, página 5. Su afición a los trenes y a los barcos era bien conocida. En San Sebastián ostentaba el título de presidente del Club Náutico.

54 TUSELL, 1997: 73. SEIDMANN, 2011: 120. Este autor insiste en la colaboración de carlistas catalanes como Bau con nacionalistas moderados, en la línea ideológica en la que tradicionalmente se habían movido hasta entonces Juan Antonio y su hijo Juan Claudio. Las comisiones, en PÉREZ DE LA CANAL, 2014: 605.

55 Hoja de servicios de Juan Claudio Güell Churruca, AMS. Ruiseñada se había afiliado a Falange el 20 de diciembre de 1937.

56 El Tribunal Médico Militar que debía clasificar su herida a efectos de indemnizaciones se refería a que en su hoja clínica constaba que sufrió el 20 de noviembre de 1938 «una otitis media traumática con repercusión laberíntica (sic) a consecuencia de onda explosiva de disparo de artillería enemiga», Hoja de servicios de Juan Claudio Güell Churruca, AMS, página 9. 
mento anhelado de hondo significado para la familia: permaneció hospitalizado en Zaragoza hasta finales de 1938.

Entretanto, no desatendió los asuntos cotidianos ligados a sus intereses. En septiembre de 1936 hizo un primer donativo a la Junta Auxiliar del gobierno civil de Cáceres para ayudar a los golpistas, propulsando así la devolución de sus fincas en la zona:

Se honra el que abajo firma de haber sido su familia de las más perseguidas por los gobiernos marxistas y de haber colaborado por todos los medios a su alcance a favor de las derechas nacionales figurando como fundador directo de los partidos que hoy salvan a España al lado de su ejército (...). No puedo por el momento enviarles mayor cantidad dadas las circunstancias actuales, pues sabrán ustedes que las fincas nos fueron expropiadas en $1933^{57}$.

El destinatario último de la carta era Eufemio Olmedo, presidente de la Comisión de Agricultura de la Junta Técnica del Estado y por tanto, «compañero» en las tareas de gobierno de la misma. Más rápida que la recuperación de tierras — que aún se demoraría hasta 1940 - , fue el regreso a posiciones de control social en aquella zona tan sensible para el negocio rentista de los Güell-Comillas. Da fe de ello la correspondencia de Churruca con el nuevo gobernador civil de Cáceres, Francisco Sáenz de Tejada, barón de Benasque, quien acepta sus indicaciones para nombrar a los alcaldes de la comarca ${ }^{58}$. Por poner solo dos ejemplos, en Casatejada señala Juan Claudio Güell Churruca que «el alcalde [es] un desastre y el párroco muy mal y ya comprendes la importancia que esto tiene en los actuales momentos», mientras que en Navalmoral «como te dije el alcalde no puede continuar por razones muchas» ${ }^{59}$.

Unas semanas después, Churruca realizó un nuevo donativo por valor de 14.500 pesetas «con destino a los gastos que ocasione en la provincia el movimiento salvador de España», cediendo además una dehesa de 700 hectáreas en Talayuela (Cáceres) para financiar la guerra con el producto de sus aprovechamientos. No todo era generosidad, sin embargo. De forma paralela, las rentas de las fincas extremeñas que no habían sido intervenidas por la reforma republicana solventaban la manutención mensual de su madre, quien permanecía sola en 'Villa Oroimena' desde la ocupación franquista de Guipúzcoa. Parece que la mala relación entre López y su esposa también fue fuente de problemas entre aquel y Churruca, encargado de los cuidados maternos.

57 Carta del conde de Ruiseñada al Gobernador Civil de Cáceres, 12/09/1936, ANC, fondo Güell-Comillas, 03.09.03.

58 Carta del conde de Ruiseñada al Gobernador Civil de Cáceres, 12/09/1936, ANC, fondo Güell-Comillas, la carta de Benasque estaba fechada el 20/08/1936.

59 Carta del conde de Ruiseñada al Gobernador Civil de Cáceres, 12/09/1936. ANC, fondo Güell-Comillas, carta de 4/12/1937. 
La devolución efectiva a los Güell-Comillas de las tierras expropiadas en Extremadura se postergó varios años, obligando a la familia a interponer sucesivas reclamaciones en las que argumentaba que la enajenación había obedecido a «razones exclusivamente políticas, pues los sindicatos católicos por la Casa fundados fueron convertidos en organizaciones marxistas con el nombre de comunidades» ${ }^{60}$. No está clara la razón de la demora. Fuera o no una represalia ante el antifranquismo recién declarado por López (a cuyo nombre figuraban inscritas realmente las fincas), el hecho es que la incondicionalidad de Churruca con el régimen no se tradujo en una recuperación inmediata pese a contar con avales técnicos favorables, luego su capacidad de influencia política ante Franco y sus hombres tuvo en esos compases iniciales un peso limitado. Su apoyo y sus antecedentes le valieron, eso sí, un simbólico retorno a Cataluña como miembro de la comisión gestora de la Diputación de Barcelona. De inmediato le expresó a Franco:

... mi satisfacción por haberme cabido la honra de haber luchado y haber sido herido a sus órdenes y de agradecerle el haberme honrado con su confianza designándome para la difícil misión que en estos momentos hemos de llevar a cabo en la Diputación Provincial de ésta, siendo siempre mi ferviente deseo de hacer honor al nombre de mis ilustres antepasados los Marqueses de Comillas sirviendo como siempre a España con el mayor entusiasmo ${ }^{61}$.

La guerra había terminado y Churruca había resultado herido como soldado del bando nacional, había desempeñado dos cargos políticos de designación directa y se había afiliado al partido único. ¿Qué opinaría su padre de todo ello?

\section{... Y UN PADRE CATALANISTA EN SU DULCE EXILIO}

Lo primero que hizo Juan Antonio Güell y López al conocer, en Mallorca, que grupos de milicianos buscaban a algunos patricios barceloneses con intenciones poco amables fue despojar a los republicanos de la condición de catalanes. Aún portaba el Llibre dels Fets de D. Jaume el Conqueridor, en el que había buscado inspiración para el discurso que preparaba, y se negaba a admitir como partícipes de su mismo relato histórico a los integrantes de un ejército que ya no es que hablase en castellano y se envolviera en otra bandera, sino que directamente encarnaba la negación «del individualismo que es

60 Carta del conde de Ruiseñada al Gobernador Civil de Cáceres, 12/09/1936. ANC, fondo Güell-Comillas, 03.09.03.

${ }_{61}$ Carta del conde de Ruiseñada a Franco, 03/03/1939, ANC, fondo Güell-Comillas, 04.07.14. 
justamente lo que hace que los catalanes se llamen catalanes» ${ }^{62}$. Para el tercer marqués de Comillas, eran ese tipo de personas las que estaban bombardeando Mallorca en los primeros días de la guerra. En cuanto trascendió que él mismo era uno de los perseguidos por anarquistas de Barcelona, su familia alertó a la casa real inglesa y el cónsul de ese país facilitó su embarque en un buque destructor que habría de evacuarlo al extranjero junto a otros refugia$\operatorname{dos}^{63}$. Hubo un temprano intento de regresar a España por la frontera francesa para afincarse en San Sebastián, donde como hemos dicho permanecía su esposa y esperaba uno de los dos automóviles propiedad de López (el otro estaba en Madrid). Pero algún falangista torció sus planes. La prensa local lo señaló como huésped indeseado, y el conde dijo regresar ofendido a Francia, desde donde proclamó su decisión «definitiva» de permanecer en el extranjero. «Podré perder toda mi fortuna o lo que llamáis mi posición social y acabar mis días en el exilio o en un hospital - replicó a los parientes que le aconsejaban integrarse en la España franquista_- pero nunca mi dignidad personal». Avancemos que no ocurrió nada de eso. Ni López dejó de disponer de un patrimonio familiar que el triunfo de Franco contribuyó a reafirmar, ni vio mermado su estatus mientras vivió en París o la Costa Azul, ni siquiera murió en el extranjero: falleció a los ochenta y un años de edad «plácidamente», a decir de Josep Tarín, en Cala d'Or (Mallorca), donde hacía ya unos años que se había instalado junto a su segunda esposa, Josefina Vidal-Ferrer, y repartía su tiempo entre la evocación de recuerdos por escrito y la visita cotidiana a establecimientos de la isla en busca de alguna buena pieza de anticuario ${ }^{64}$. Es cierto que, por el camino, se había convertido en un aristócrata algo molesto para los cuadros de la dictadura, que no lograban explicarse (si no era desde la impostura) cómo un personaje de su rango pretendía mantenerse equidistante entre uno y otro bando, articulando para colmo un discurso catalanista de sustrato cada vez más político con el que terminó por reelaborar su historia de exiliado. Pero la persecución por ello no fue encarnizada y acabó teniendo, incluso, algo de condescendiente.

Apenas terminada la II Guerra Mundial, un funcionario franquista detectó y envió al fiscal de la Causa General un ejemplar del diario que López acababa de publicar en Mónaco, advirtiendo en él pasajes desagradables ${ }^{65}$. Desde el hecho mismo de estar escrito en francés, el Journal d'un expatrié catalan irri-

62 GÜELL, 1946: 2-3. En su tesis doctoral, relativa al códice medieval del que se había dotado una pequeña localidad del noreste catalán, Juan Antonio Güell ya había observado el caso de una comunidad de espíritu profundamente individual, véase GÜELL, 1902.

63 GÜELL, 1902: 8.

64 TARÍN, 84 (Barcelona, 1975): 102-103. GÜELL, 1946: 15.

65 Todo lo que sigue está tomado de las anotaciones manuscritas que el censor realizó sobre un ejemplar del Journal d'un expatrié catalan que hoy se conserva en Salamanca bajo custodia del CDMH. 
tó al encargado de revisar aquel texto. Era una especie de alegato raro, donde un marqués renegado repudiaba el régimen surgido de la guerra, cuestionaba por injusto el reparto de la tierra en España (pese a ser él mismo uno de los mayores propietarios del país) y, entre otras cosas, decía soñar con un Estado confederal con capital en Alcalá de Henares. «¿Qué fresco es Vd., compadre!», anotó en el margen de una de las páginas el censor. De cobarde tachó a López por huir por mar a Francia, máxime cuando «en la zona roja este buen señor estaría en ese momento en el depósito de cadáveres o en la cárcel». Le reprochó su frivolidad por haber visitado Italia, e incluso India y Singapur en la primavera de 1937, «mientras España se desangra[ba] sin que V. E. luche por ningún ideal... que no sea el de viajar», y se burló del dramatismo con que López relató su posterior instalación en un hotelito parisino donde preveía un agravamiento de su bronquitis por los efectos del frío y de la lluvia: «¡Qué heroico, Sr. Marqués!». La retahíla no terminó ahí. Junto a la cobardía y la vacuidad («¿Es posible que el lector francés no desprecie a este snob?», se preguntaba el funcionario franquista), se le endosaban a López dos etiquetas más, las de «magnífico traidor» y evidente «farsante». Lo primero, de acuerdo con la retórica de apropiación de la españolidad que practicó el bando vencedor en la guerra, porque el representante del régimen no concebía el rechazo de quien sobre el papel resultaba un natural correligionario, si no era observando su contaminación por patrones importados de Inglaterra o Francia («está Vd. hecho un extranjero imponente», fue la síntesis de esta idea). En cuanto a las acusaciones de impostura, transversales en los apuntes a lápiz que dejó el censor, todas ellas fueron a parar a la «buena vida» de la que el marqués parecía disfrutar en efecto mientras escribía su catecismo político, por más que subrayara lo terrible de su condición de exiliado, o que en una ocasión se desvelara recordando la mirada implorante de un perro pequinés que vagaba por alguna de las villas francesas evacuadas en la Costa Azul al comienzo de la guerra. Replicaba a esto último el funcionario: «Es la primera noche que no duerme S. E. de corazón tan sensible. Los miles de sacerdotes y monjas asesinados por los rojos no le quitan el sueño». Lo antiespañol corría parejo a lo antirreligioso.

Pero donde sin duda el censor cargó las tintas de su juicio, más visceral que brillante, apurando el lapicero con fuerza para regañar a un semejante extraviado, y no con la rotundidad de quien fustiga a un enemigo que desearía aniquilar, fue en las páginas del libro donde López alumbraba un programa político inconcebible para el franquismo. ¿Cómo encajar, desde una dictadura centralista aún en plena construcción, la sola idea del conde de postular una confederación de Estados formada por «Galicia, País Vasco y Navarra, Cataluña, Valencia, Baleares, Canarias y España propiamente dicha», con representación permanente en Alcalá de Henares, y simbolizada en una bandera ecléctica de fondo blanco que nada tenía que ver con la que había ganado la 
guerra? Visiblemente contrariado, el censor respondía a esto con otra pregunta: « $i \mathrm{Vd}$. aceptaría que la bandera catalana desapareciera y en lugar de las barras le pusieran unas zanahorias?». A comienzos de 1945, y en vísperas por tanto del Manifiesto de Lausana con el que Don Juan de Borbón reclamó la restauración de la Monarquía en España, López fantaseaba con un gran cambio político que habría de completarse en dos fases sucesivas. Franco dimitiría en favor de un regente que bien podría ser Alfonso de Orleans, quien a su vez autorizaría la formación de un gobierno provisional de concentración compuesto, entre otros, por José María Gil-Robles, Juan Negrín, Indalecio Prieto, el conde de Rodezno y el propio López. Él mismo fundaría un partido llamado Confederación Democrática con el que estaba seguro de recabar el apoyo de las regiones periféricas, a partir de tres principios: la soberanía de cada Estado o minoría nacional, la salvaguarda de la unidad del Estado español en la persona de un rey y el soporte de un ejército confederal, y un amplio concierto con las grandes potencias para garantizar el prestigio exterior del nuevo país de países. Con este programa haría campaña. Pero en todo caso el colofón del proceso debían ponerlo unas elecciones generales («bonita y nueva palabra», apuntó aquí el censor como prueba de que se iba enfureciendo) donde se decidiría, y acataría, entre el retorno a la Monarquía o la recuperación de la República. Estalló el funcionario: «Y vuelta a empezar con el Frente Popular. ¡V. E. Es un estadista!». Le causaba pavor, o vergüenza ajena, la fragmentación que a su juicio postulaba López, y así se ocupó de expresarlo en sus últimas anotaciones. Cuando el conde se ufanó de que su hipotético partido contaría con la simpatía de Galicia, Navarra, País Vasco, los Países Catalanes y las islas Canarias, el censor añadió: «Y de Vallecas, no se le olvide». Y para cerrar su lectura crítica, también en clave madrileñista, condensó su escepticismo no sin cierta confusión: «Ya, ya. Cataluña, Navarra, Galicia, Vasconia, Andalucía, Vallecas, Pueblo Nuevo (...). Repúblicas soviéticas, después de asesinar al clero de tercera, y luego a cantar el nacimiento, etc.». Se refería al deseo del nacimiento de un mundo mejor con el que López culminaba su diario en mayo de 1945, coincidiendo con el fin de una guerra en la que en todo momento se había alineado con el bando aliado.

Dos apuntes más sobre el pensamiento político que el tercer marqués de Comillas desarrolló en su Journal d'un expatrié catalan. Uno viene a cuento de este último (y nada casual) adjetivo. Aunque ya la había avanzado años atrás, la contraposición entre Castilla y Cataluña con ventaja para ésta se agudizó de tal modo, que a la altura de los años cuarenta López hablaba de esa «parte inmutable de España, patria de Don Quijote, cuna de la Inquisición» como una «tierra seca y árida» habitada por hombres austeros y bajitos que desconocen las nanas, las canciones de amor y el baile mismo. En el discurso del conde, los castellanos, además mayormente incultos, estarían incapacitados para asumir y ejercer la democracia por su «agotamiento espiritual», pero 
sobre todo porque «la esencia de la espiritualidad castellana es la intransigencia» y reconocer libertades a otros equivaldría, en su supuesta mentalidad, a renunciar a la propia dignidad. La segunda nota debe recoger el diagnóstico general que López hacía en su libro de la España franquista. Cuestionaba ya lo hemos dicho-, el reparto de la riqueza en el país, que le resultaba, decía, «demasiado irritante»: los latifundios permanecían en manos de ricos tras una «inconcebible» devolución a la nobleza de tierras que habían sido expropiadas por la República, cuando el asunto podría haberse solventado con unas buenas indemnizaciones. La militarización de la política y aun de la sociedad, un problema en sí mismo, iba en aumento. Cercenar todo intento de autonomía regional no haría sino posponer la solución de un asunto grave. Y el clericalismo «espectacular» con el que Franco y los suyos respondían al problema religioso solo podría traer, a juicio de López, «más horas trágicas» a España. «Se comenta solo — despachaba el censor-. Y aún así, ¿le perdonarán la vida los comunistas?».

Todo esto se explicitaría hacia 1946, mientras Ventosa lideraba el lobby monárquico con la aquiescencia de Kindelán, pero hacía ya tiempo que un ruido de fondo afectaba a todas las noticias sobre los comportamientos y opiniones políticas de López que llegaban (o que no llegaban) a España, donde su hijo Churruca jaleaba al franquismo. En público excusaba la ausencia de su padre «delicado de salud, sometido a régimen de reposo» en Francia ${ }^{66}$, pero todos comprendían que algo de mayor calado debía ocurrir cuando hasta las comunicaciones entre ambos, en principio directas, a través más tarde del consulado en Hendaya, ingresaron en una especie de clandestinidad a mediados de 1940, en cuanto un familiar retornado indicó que las cartas a López deberían dirigirse, en lo sucesivo, a nombre de «S. A. A. Beauharnais. Bealieu-sur Mer. Francia» ${ }^{67}$. Las alteraciones en el correo producidas por la guerra europea tampoco ayudaron mucho. Escribía Churruca al cónsul en Niza, en julio de 1940: "Ante todo mil gracias por tu telegrama dándome noticias de Papá. Ya supondrás lo intranquilo que yo estaba con motivo de todo lo que está sucediendo» ${ }^{68}$.

${ }^{66}$ Carta de Juan Claudio Güell a Anita Hidalgo, 16/05/1940, ANC, fondo GüellComillas, 04.02.02.

67 Carta de Juan José Ferrer-Vidal a Juan Claudio Güell, ANC, fondo Güell-Comillas, 29/05/1940.

${ }^{68}$ Carta de Juan Claudio Güell a Alejandro Pons, ANC, fondo Güell-Comillas, 01/07/1940.

Hispania, 2018, vol. LXXVIII, $n^{\circ}$. 260, septiembre-diciembre, págs. 787-816, ISSN: 0018-2141, e-ISSN: 1988-8368 https://doi.org/10.3989/hispania.2018.019 


\section{TRES GUERRAS MÁS TARDE: «EL HOMBRE MÁS ATAREADO DE ESPAÑA»}

Con el padre vagando sin mayores complicaciones, pues, por la Francia ocupada, el hijo se aprestó a ratificar su compromiso con el bando que acababa de vencer la guerra en España. Por todo lo que hizo Churruca durante esos años, desde 1939 hasta su fallecimiento en 1958, se ganaría el apelativo de «uno de los hombres más vitales y más atareados» del país. Se diría, incluso, que murió «víctima de su actividad» ${ }^{69}$ al servicio de sus negocios y de la solución monárquica al franquismo que acabaría patrocinando (sin renunciar al autoritarismo ni al propio Franco), bautizada de hecho como «operación Ruiseñada». Mientras mantenía una profusa correspondencia con los generales monárquicos de mayor peso en el incipiente régimen - Vigón, Aranda, Varela, Kindelán ${ }^{70}$ - Churruca se confirmó en su condición de algo así como jefe de la Casa de la Reina Victoria Eugenia, vinculando a los monárquicos del interior con la corte de Don Juan tras la muerte de Alfonso XIII. No confrontó con Franco, sino que buscó tender puentes entre él y la monarquía ${ }^{71}$. Así, en 1940 Churruca no duda en integrarse en el Consejo de la Hispanidad, el órgano propagandístico-cultural creado desde el ministerio de Asuntos Exteriores cuya orientación a favor de Mussolini y Hitler condujo hasta su reconversión en el Instituto de Cultura Hispánica cuando la victoria aliada se vio cercana ${ }^{72}$. Tampoco renunció al reconocimiento de sus esfuerzos bélicos, solicitando (y consiguiendo) en 1942 la Medalla de Sufrimientos por la Patria y renunciando a los correspondientes derechos de pensión ${ }^{73}$.

Antes, en diciembre de 1939, Juan Claudio Güell Churruca fue recibido por Franco, y parece que esa audiencia desbloqueó al fin la devolución de las fincas extremeñas a los Güell-Comillas. Gravitó, entonces sí, hacia el núcleo del franquismo. El dictador respaldaría pronto el lanzamiento de la causa de beatificación del segundo marqués de Comillas auspiciada por el propio Churruca, y éste recibiría además un importante encargo. Según relata Viñas, los lingotes de oro procedentes de la suscripción nacional viajaron en mayo de 1940 hasta Estados Unidos para ser intercambiados por petróleo, tan escaso en aquella España. Custodiado por la Armada, el barco elegido fue el Marqués de Comillas, uno de los pocos buques insignia de la Trasatlántica que

69 La Vanguardia, 25/04/1958: 1. ABC, 25/04/1958: 27-28.

70 ANC, fondo Güell-Comillas, 04.08.05.

71 ARÓSTEGUI, 2002: 77-111.

72 DELGADO, 1992: 274.

73 Hoja de servicios de Juan Claudio Güell, AMS, página 8. La instancia solicitando la medalla y renunciando a la pensión la dirige al general Varela como ministro del Ejército el 15/10/1941. En esta época, Churruca realiza todas sus gestiones desde el Palau Moja de Barcelona.

Hispania, 2018, vol. LXXVIII, nº. 260, septiembre-diciembre, págs. 787-816, ISSN: 0018-2141, e-ISSN: 1988-8368 https://doi.org/10.3989/hispania.2018.019 
sobrevivieron a la guerra ${ }^{74}$. Güell Churruca era muy conocido de hecho por haber heredado la presidencia de la gran naviera familiar, y a su frente trató de rehabilitar su flota, inyectar en el negocio (como había querido su padre) un valor turístico añadido y recuperar las rutas con América $^{75}$. Tan bien comprendió qué parte del futuro pasaba por Estados Unidos, que tras el cargamento de oro viajó allí él mismo. En 1944 se embarcó hacia Nueva York, donde, entre otras actividades, adquirió un remolcador bautizado con su título nobiliario. Tras subrayar su vínculo con la casa Ford, en la que la familia estaba interesada, su necrológica remacharía: «quedó tan deslumbrado por aquella Norteamérica de posguerra, que adoptó el modelo de vida de los grandes hombres de empresa, los Tycoons» ${ }^{76}$. Sabemos por Díaz Hernández que pasó cuatro meses en Estados Unidos tras el fin de la II Guerra Mundial, con el posible objetivo de hacer «gestiones financieras y conocer personalidades que pudieran facilitar la restauración» de la monarquía en comunión con Franco ${ }^{77}$.

A su regreso a España, Churruca fundaría el Banco Atlántico a partir de la compra de la pequeña banca catalana Nonell, en lo que parece un efecto directo de modernizar el modus operandi de su actividad financiera y empresarial. De este modo, el Atlántico fue la nueva banca moderna de la familia, sustituyendo a la Banca López Bru y dejando el Hispano Colonial y sus activos en manos del Banco Central, de cuyo consejo de administración formaba parte, al igual que de la aseguradora Vitalicio. Los negocios familiares prosperaban y se multiplicaban. Aun exiliado en Francia y opositor «de baja intensidad» a Franco al menos desde un plano teórico, el padre díscolo, Juan Antonio Güell López, seguía presentando su declaración de la renta al régimen franquista gracias a la mediación de su hijo. Su participación en 25 sociedades le reportaba todavía más dinero tras la guerra civil: 109.675 pesetas en 1941, cantidad que se duplicaría al año siguiente (208.541) y que mejoraba en sustancia aquellas 66.713 pesetas recibidas como rendimientos del capital mobiliario en 1935, en vísperas del golpe. Es cierto que López ya no ingresaba ahora los sueldos que entonces había percibido como consejero de varias empresas, pero también que sus reportes como propietario no dejaban de crecer. A 608.250 pesetas ascendían las retribuciones brutas como rentista de la

74 VIÑAS, 1976: 423. Para la causa de beatificación de López Bru, véase FAES, 2009: 367-390. Ruiseñada aportó inicialmente más de 100.000 pesetas a los encargados de velar por su buena marcha, los jesuitas vinculados al seminario pontificio de Comillas, y su financiación a esta institución incluyó un viaje a Comillas del joven Marcial Maciel, futuro fundador de los Legionarios de Cristo, acompañado de más de 30 novicios (RODRÍGUEZ, 2011: 38). Marciel denomina gráficamente a Churruca como el «eterno funambulista» entre Franco y la causa monárquica.

75 RODRIGO, 2001: 328.

76 La Vanguardia, 25/04/1958: 1. ABC, 25/04/1958: 27-28.

77 DÍAZ HERNÁNDEZ, 2008: 293. 
posguerra, gracias a las más de dos docenas de fincas rústicas y urbanas que aún poseía en 1941 en Cataluña, Toledo, Cáceres y Santander. Aproximadamente el doble de lo que se había embolsado en ese concepto durante el ejercicio contable previo a la contienda ${ }^{78}$.

El flujo de parte de esa fortuna hacia Francia fue posible, insistimos, gracias a la plena integración de Churruca en el régimen franquista. Él firmaba por delegación las declaraciones de su padre huido, y tenía muy presente que lo más sustancial de la riqueza familiar seguía residiendo en la posesión de tierras, algunas de las cuales acababa de recuperar. Ambos, padre e hijo, fallecerían en 1958 aparentemente alejados entre sí, pero muy unidos por un ingente patrimonio común.

\section{TIERRA DE POR MEDIO: ALGUNAS CONCLUSIONES}

Gracias a las mimbres trenzadas por los empresarios Juan y Eusebio Güell, por un lado, y Antonio y Claudio López, por el otro, los Güell-Comillas llegaron a la crisis de la Restauración con un firme patrimonio familiar asentado sobre todo en la posesión de tierras, pero lo suficientemente diversificado como para garantizar su pervivencia. Junto a esa solidez económica, y a una historia familiar cuajada de vidas que podían resultar ejemplares (poderosos self-made-men, mecenas e incluso un candidato a la beatificación), los miembros de la tercera y cuarta generación heredaron además una estimable capacidad de influencia política y empresarial. ¿Cómo gestionaron todo ello Juan Antonio Güell López y su hijo Juan Claudio Güell Churruca, en un periodo convulso como fue la España de entreguerras? Es revelador, de entrada, un indicador cuantitativo: lejos de acusar la inestabilidad, el patrimonio de los Güell-Comillas no solo resistió a las guerras europeas y española, sino que salió reforzado de ellas. La familia mantuvo su riqueza gracias a la pervivencia de sus importantes participaciones en negocios que hallaron su encaje en una economía cambiante, pero la clave estuvo en la conservación - o recuperación-, de la importante red de bienes raíces (tierras, significativamente) que ya al comenzar el siglo anunciaba el peso que los apellidos Güell y López tenían en España.

En lo político, durante el periodo estudiado, los Güell-Comillas reforzaron los lazos con la Casa Real heredados de sus padres y abuelos, y mantuvieron la tradicional apuesta familiar por la monarquía como el sistema más idóneo para regir una España en la que Cataluña debía ocupar un lugar relevante, con

78 Contribución de la renta de Juan Antonio Güell para 1941 y 1942, ANC, fondo GüellComillas, 05.09.02. Expediente de Juan Antonio Güell en la contribución de la renta de 1935, AHN, FC, Hacienda, 7098, exp. 171. 
el rey como estandarte de una autoridad y prestigio nacionales que a menudo se enunciaron como un deseo. Ahondaron, pues, en el juego habitual de mutua seducción entre las más potentes familias catalanas y los Borbones restaurados en el trono, pero debieron afrontar la crisis del sistema político bajo el que sus apellidos habían prosperado. Llegado ese momento, nunca contemplaron una solución que no fuera netamente conservadora. Alentaron el golpe de Primo de Rivera y al mismo tiempo cerraron filas en torno a una monarquía en horas bajas. Episodios como el del Patronato Nacional del Turismo, un organismo que los Güell controlaron sin discusión en los años veinte, nos hablan de un conato de modernización elitista que quedó cercenado por los vaivenes políticos, pero que nació ya matizado por la mentalidad de ribetes aristocratizantes que en la práctica le imprimieron sus impulsores.

El estudio de caso que aquí cerramos no puede sino leerse como una prueba más del peso sustantivo que las élites catalanas tuvieron en la praxis y configuración políticas de la España de entreguerras, incluyendo el primer franquismo. Tal vez la principal contribución de los Güell-López en este aspecto fue el ensanche «desde arriba», al menos retórico, del campo de juego disponible para cualquier conservador en España durante la tortuosa primera mitad del XX, especialmente hacia y desde Cataluña. Padre e hijo supieron redefinir las tradicionales apuestas conservadoras de sus predecesores y adaptarlas a una realidad política cambiante, extendiendo la capacidad de influencia del clan a cuantos espacios políticos «respetables» se abrieron tras el estallido de la guerra civil. Al formular un personal y templado regionalismo que enojó al franquismo por entender que tenía mucho de impostura, exiliado en Francia más como un observador de lujo de la Segunda Guerra Mundial que como un disidente en peligro (su condena a muerte la habían dictado los perdedores de la guerra en España, no los golpistas), Juan Antonio Güell López le proporcionó dos cosas al catalanismo de matriz conservadora: la supuesta encarnación ejemplar de un martirio que para él desde luego no lo fue tanto y, en especial, una actualización del discurso posibilista, escurridizo, graduable a conveniencia y en última instancia deudor de la monarquía que únicamente concebía Cataluña como sujeto político pasándola por el tamiz del orden, la buena estética y la refinación de sus símbolos e incluso de sus dirigentes.

No distaba mucho esa concepción de la que hombres como Joan Ventosa o el propio Juan Claudio Güell Churruca debían llevar consigo al tomar posiciones en el gobierno de Burgos, sugiriendo a los franquistas que aquel catalanismo patricio y moderado podía quizá no ser tan malo ${ }^{79}$. Pero Ventosa hubo de conformarse con ver a uno de sus hijos, Ignasi, convertido en uno de los oficiales de complemento del ejército golpista recompensados con cargos

79 RIQUER, 1996: 96. 
públicos en los albores del nuevo régimen, mientras que Churruca obtuvo eso para él mismo y más ${ }^{80}$ : tras haber puesto los engranajes familiares al servicio de la trama civil que culminó en el golpe de 1936, ganó crédito ante Franco y se lanzó a un progresivo aumento de su capacidad de influencia política que culminaría en la llamada «operación Ruiseñada», fuera ya del tracto temporal elegido para este estudio.

Es posible que se produjera cierto distanciamiento - tierra de por medio-, entre padre e hijo fruto de la separación de facto de Juan Antonio Güell respecto a su esposa, pero las apariencias se siguieron manteniendo y la intensidad de los intereses de la familia continuó brillando en un amplio campo de actuación cuadrangular que comprendía cuatro vértices básicos (Comillas y el Cantábrico oriental, por origen; Barcelona, por tradición; Extremadura y Toledo por la posesión de grandes fincas rústicas que sustentaban el patrimonio; y Madrid, por necesidad). Como consecuencia de todo ello, y gracias a la solidez de los hechos económicos, la proyección de los Güell-Comillas se extendió tanto por el polo madrileño del que irradiaba el poder franquista, como por la Barcelona que añoraba un pasado también ordenado y próspero para sus «buenas» familias, con las que el nuevo régimen tuvo que contar.

\section{BiBLIOGRAFÍA}

Alvarado, Joaquim y Parejo Moruno, Francisco, Industria i comerç del suro. Els Torrellas de Tossa, 1879-1923, Tossa, Centre d'Estudis Tossencs, 2016.

Aróstegui, Julio, Don Juan de Borbón, Madrid, Arlanza, 2002.

Bertrán y Güell, Felipe, Preparación del Alzamiento Nacional, Valladolid, Librería Santaren, 1939.

Burdiel, Isabel, «Historia política y biografía:más allá de las fronteras», Ayer, 93 (Madrid, 2014): 47-83.

Cabana, Francesc (coord.), Cien empresarios catalanes, Madrid, LID, 2006.

Calleja y López, Juan José, Yagüe: un corazón al rojo, Barcelona, Juventud, 1963.

Del Rey Reguillo, Fernando y González Calleja, Eduardo, La defensa armada contra la revolución. Una historia de las guardias civicas en la España del siglo XX, Madrid, CSIC, 1995.

Delgado Gómez-Escalonilla, Lorenzo, Imperio de papel: acción cultural y política exterior durante el Primer Franquismo, Madrid, CSIC, 1992.

Díaz Hernández, Onésimo, Rafael Calvo Serer y el grupo Arbor, Valencia, PUV, 2008.

Faes Díaz, Enrique, Claudio López Bru, Marqués de Comillas, Madrid, Marcial Pons, 2009.

80 MARÍN, 197 (Barcelona, 1995): 22-27. 
Farrás, Andreu, Els Güell, la història d'una de les famílies més influents a Catalunya els últims dos segles, Barcelona, Edicións 62, 2016.

Fontbona, Francesc, «Joan Antoni Güell i López, comte de Güell», Butlletí de la Reial Acadèmia Catalana de Belles Arts de Sant Jordi, 22 (Barcelona, 2008): 193-198.

Gil Robles, José María, No fue posible la paz, Barcelona Planeta-Horas de España, 1968.

González Calleja, Eduardo, Contrarrevolucionarios: radicalización violenta de las derechas durante la II República, 1931-1936, Madrid, Alianza Editorial, 2011.

González Cuevas, Pedro Carlos, Acción Española: teología política y nacionalismo autoritario en España (1913-1936), Madrid, Tecnos, 1998.

Güell López, Juan Antonio, Ensayo sociológico sobre un Código de la Edad Media, Madrid, Ricardo Fe, 1902.

Güell López, Juan Antonio, Apuntes de recuerdos, Barcelona, Imprenta gráfica de El Siglo XX, 1926-1929 (varios tomos).

Güell López, Juan Antonio, Journal d'un expatrié catalan (1936-1945), Mónaco, Editions du Rocher, 1946.

Marín, Martí, «La classe politica local a la Catalunya franquista: dues Espanyas, dues Catalunyes», L'Avenç, 197 (Barcelona, 1995): 22-27.

Moreno, Ana, «La estrategia atlántica. Élites económicas e intereses turísticos en la España de Primo de Rivera», Historia Contemporánea, 41 (Madrid, 2010): 481-508.

Peña González, José, «La monarquía en España de 1939 a 1975», Beresit: Revista Interdiciplinar cientifico-humana, 5 (Toledo, 2003): 123-146.

Pérez de la Canal, Miguel Ángel, «La restauración administrativa del Movimiento Nacional establecida en 1 de octubre de 1936», Anuario de Historia del Derecho español, 84 (Madrid, 2014): 581-619.

Pradas Baena, María Amàlia, L'anarquisme i les lluites socials a Barcelona, 19181923: la repressió obrera i la violencia, Barcelona, Publicacions de l'Abadia de Montserrat, 2003.

Quiroga Fernández de Soto, Alejandro, «Nación y reacción. El nacionalismo conservador español y la crisis de la Restauración», en Francisco Romero Salvadó y Ángel Smith (eds.), La agonía del liberalismo español. De la revolución a la dictadura (1913-1923), Granada, Comares, 2014: 197-222.

Riesco Roche, Sergio, La reforma agraria y los orígenes de la guerra civil, Madrid, Biblioteca Nueva, 2005.

Riquer, Borja de, L'últim Cambó (1936-1947): la dreta catalanista davant la guerra civil $i$ el franquisme, Vic, Eumo, 1996.

Robledo Hernández, Ricardo, «Sobre el fracaso de la reforma agraria andaluza en la Segunda República», en Manuel Luis González de Molina (coord.), La cuestión agraria en la historia de Andalucía: nuevas perspectivas, Sevilla, Junta de Andalucía, 2014: 63-96.

Rodrigo y Alharilla, Martín, Los Marqueses de Comillas, 1817-1925. Antonio y Claudio López, Madrid, LID Editorial, 2001. 
Rodríguez, Jesús, La confesión. Las extrañas andanzas de Marcial Maciel y otros misterios de la Legión de Cristo, Barcelona, Debate, 2011.

Romero Maura, Joaquín, La rosa de fuego: el obrerismo barcelonés de 1899 a 1909, Madrid, Alianza, 1989.

Ruiz Alonso, José María, «El sistema de partidos en el Toledo de la II República», en Manuel Álvarez Tardío y Roberto Villa García, Nuevos estudios sobre la cultura política en la II República (1931-1936), Madrid, Dykinson, 2011: 41-69.

Seidmann, Michael, The victorious contrarrevolution, Wisconsin, The Wisconsin University Press, 2011.

Tarín Iglesias, Josep, «El tercer marqués de Comillas, un catalanista insólito», Historia y vida, 84 (Madrid, 1975): 90-103.

Tusell, Javier, «La Junta Técnica del Estado», en La Guerra Civil Española: El avance rebelde, Barcelona, Ediciones Folio, 1996: 70-83.

Viñas, Ángel, El oro español en la guerra civil, Madrid, Ministerio de Hacienda, 1976.

Recibido: $14 / 12 / 2017$

Aceptado: 25/07/2018 